\title{
Interpreting Permanent Shocks to Output When Aggregate Demand May Not be Neutral in the Long Run
}

\author{
John W. Keating* \\ University of Kansas \\ Department of Economics \\ 334 Snow Hall \\ Lawrence, KS 66045 \\ web page: http://www.people.ku.edu/ jkeating/ \\ e-mail: jkeating@ku.edu \\ phone: (785)864-2837 \\ fax: (785) $864-5270$
}

February 17, 2012

Key Words: vector autoregression, identification restrictions, moving average representations, aggregate demand and supply theory, permanent and transitory shock decomposition

JEL Codes: C32, C52, E3

Abstract: This paper studies Blanchard and Quah's (1989) statistical model of permanent and transitory shocks to output using a set of arguably more plausible structural assumptions. Economists typically motivate this statistical model by assuming aggregate demand shocks have no long-run effect on the level of output. Many economic theories are, however, inconsistent with that assumption. We reinterpret this statistical model assuming a positive shock to aggregate supply lowers the price level and in the long run raises output while a positive shock to aggregate demand raises the price level. No assumption is made about the long-run output effect of aggregate demand. Based on these assumptions, we show that a puzzling finding from the empirical literature implies that a positive (negative) aggregate demand shock had a long-run positive (negative) effect on the level of output in a number of pre-World War I economies.

* I thank Pok-sang Lam (the editor) and two referees for very helpful suggestions. I also thank Shigeru Iwata, Robert Rasche, Ellis Tallman, Chris Waller, Tao Zha, and seminar participants at the Atlanta Fed, University of Georgia, University of Kansas, University of Kentucky, University of Notre Dame, Purdue University, University of Missouri, the Econometric Society Summer Meetings, the Midwest Econometrics Group Meeting, the Midwest Macroeconomic Conference, and the Missouri Economics Conference for helpful comments on various earlier versions of the paper. I assume responsibility for any errors and omissions. Support from the General Research Fund at the University of Kansas is gratefully acknowledged. 


\section{Introduction}

This paper shows how alternative structural assumptions can be used to structurally interpret effects of a permanent shock to output in the Blanchard and Quah (1989) decomposition. Instead of the standard - but questionable - assumption that aggregate demand shocks are long-run neutral for output, we impose constraints primarily on the dynamic responses of variables to structural shocks. Specifically, we assume that an aggregate supply shock that permanently raises(lowers) output will cause the price level to fall(rise) and that an aggregate demand shock that initially raises(lowers) output causes the price level to rise(fall). ${ }^{1}$ It is important to emphasize that these assumptions are not used to construct or identify a statistical model, but rather to interpret findings from Blanchard and Quah's popular statistical model.

A primary motivation for this paper is to understand a puzzling empirical result. Keating and Nye (1998) found systematically different impulse responses across different sample periods. They defined the postwar as the period that followed World War II and the prewar as the period that preceded World War I. They found that in the postwar period the impulse responses from the statistical model are typically consistent with textbook macro theory. ${ }^{2}$ For that period the statistical model finds that the permanent shocks almost always behave like aggregate supply and the temporary shocks almost always behave like aggregate demand. However, for most of the prewar economies in their study, Keating and Nye (1998) found that a permanent increase in output is associated with an increase in the price level. These prewar responses to permanent shocks are inconsistent with the simple textbook model of aggregate supply.

Based on the alternative set of structural assumptions we show that if the permanent shocks move price and output in the same direction, then a positive aggregate demand shock has a permanent positive effect on output. In other words, the prewar price responses to permanent shocks don't merely reject Blanchard and Quah's structural interpretation of the model. They indicate that stimulative aggregate demand had a positive effect on output in the long run if our structural assumptions are valid. ${ }^{3}$ This finding is interesting and potentially important because economic theories predict that the long-run effect 
of aggregate demand on output can be positive, negative or zero depending on the source(s) of aggregate demand movements and the underlying structure of the economy.

The next section of the paper presents a version of Blanchard and Quah's statistical model and a linear economic structure. Section III shows how the statistical model and the structure are mapped into the reduced-form VAR. This mapping provides a means of characterizing how the statistical model and the structure are related. Section IV proposes plausible restrictions on the responses of price and output to aggregate demand and supply shocks, reviews the relevant empirical findings and develops our main result. The paper concludes by briefly discussing implications and potentially useful topics for future research.

\section{The Structure and the Model}

This paper is concerned with two representations of the data, one obtained from a statistical model and the other that pertains to the true structure. Both of these are defined in terms of moving average representations. The structural moving average representation describes the dynamic responses of variables to structural shocks. The statistical model's moving average representation represents the dynamic responses to the temporary and permanent shocks to output from Blanchard and Quah's decomposition. Their decomposition is obtained by imposing a particular set of identification restrictions on a reduced-form VAR model.

\section{A. The VAR}

A VAR is a system of equations in which each variable is a function of lagged endogenous variables and a serially uncorrelated error:

$$
\beta(\mathrm{L}) \Delta \mathrm{X}_{\mathrm{t}}=\mathrm{e}_{\mathrm{t}}
$$


with $\mathrm{X}_{\mathrm{t}}=\left(\mathrm{Y}_{\mathrm{t}}, \mathrm{P}_{\mathrm{t}}\right)^{\prime}$ the vector of variables consisting of the log of real output and the log of the price level, $e_{t}$ the vector of residuals and $\Delta$ the first difference operator. $\beta(L)=I-\beta_{1} L-\beta_{2} L^{2} \ldots-\beta_{\kappa} L^{k}$ represents the coefficients in the VAR with the identity matrix and each $\beta_{j}$ for $j=1,2, \ldots, \kappa$ a $2 \times 2$ matrix, and $\kappa$ is the number of lags in the VAR. Deterministic features such as constants, deterministic trends or time-based dummy variables that might be essential for conducting a valid empirical analysis have been omitted without loss of generality.

\section{B. The Structural Moving Average Representation}

We assume the economic structure has the following moving average representation:

$$
\Delta \mathrm{X}_{\mathrm{t}}=\theta(\mathrm{L}) \varepsilon_{\mathrm{t}}
$$

where $\varepsilon_{\mathrm{t}}=\left(\varepsilon_{\mathrm{t}}^{\mathrm{S}}, \varepsilon_{\mathrm{t}}^{\mathrm{D}}\right)^{\prime}$ is the vector of structural shocks to aggregate supply and aggregate demand, $\theta(L)=\theta_{0}+\theta_{1} L+\theta_{2} L^{2}+\ldots=\sum_{j=0}^{\infty} \theta_{j} L^{j} \quad$ specifies the dynamic responses of $\Delta Y$ and $\Delta P$ to these structural shocks and each $\theta_{j}$ is a $2 \times 2$ matrix of structural parameters with $\theta_{j}=\left[\begin{array}{ll}\theta_{j}^{Y S} & \theta_{j}^{\mathrm{YD}} \\ \theta_{j}^{\mathrm{PS}} & \theta_{j}^{\mathrm{PD}}\end{array}\right]$ for all j. If aggregate demand and supply shocks are uncorrelated, which is indeed the usual assumption, ${ }^{4}$ then it is convenient to normalize these shocks to have variances equal to one: $E \varepsilon_{\mathrm{t}} \varepsilon_{\mathrm{t}}^{\prime}=\mathrm{I}$.

Recursive substitution transforms equation (2), the system for first differenced variables, into a system in levels, from which the dynamic responses of variables to structural shocks are obtained:

$$
\frac{\partial \mathrm{X}_{\mathrm{t}}}{\partial \varepsilon_{\mathrm{t}-\mathrm{k}}}=\sum_{\mathrm{j}=0}^{\mathrm{k}} \theta_{\mathrm{j}} \equiv \Phi_{\mathrm{k}}
$$

where $\Phi_{k}$ is defined as the k-th partial sum of $\theta(\mathrm{L})$. This redefinition is helpful when we make assumptions about how each shock affects the level of each variable. Note that $\Phi_{\mathrm{k}}$ is a $2 \times 2$ matrix: 


$$
\Phi_{\mathrm{k}}=\left[\begin{array}{ll}
\Phi_{\mathrm{k}}^{\mathrm{YS}} & \Phi_{\mathrm{k}}^{\mathrm{YD}} \\
\Phi_{\mathrm{k}}^{\mathrm{PS}} & \Phi_{\mathrm{k}}^{\mathrm{PD}}
\end{array}\right]
$$

where $\Phi_{\mathrm{k}}^{\mathrm{vi}}=\sum_{\mathrm{j}=0}^{\mathrm{k}} \theta_{\mathrm{j}}^{\mathrm{vi}}$ for $\mathrm{v}=\mathrm{Y}, \mathrm{P}$ and $\mathrm{i}=\mathrm{S}, \mathrm{D}$.

By letting k go to infinity in (3) we obtain:

$$
\lim _{\mathrm{k} \rightarrow \infty}\left(\frac{\partial \mathrm{X}_{\mathrm{t}}}{\partial \varepsilon_{\mathrm{t}-\mathrm{k}}}\right)=\sum_{\mathrm{j}=0}^{\infty} \theta_{\mathrm{j}}=\theta(1)
$$

where $\theta(1)$ comes from setting $L=1$ in $\theta(L)$ and is written as:

$$
\theta(1)=\left[\begin{array}{ll}
\Theta_{\mathrm{YS}} & \Theta_{\mathrm{YD}} \\
\Theta_{\mathrm{PS}} & \Theta_{\mathrm{PD}}
\end{array}\right]
$$

These parameters represent the long-run effects of an aggregate supply or an aggregate demand shock on price or output. Clearly, $\Phi_{\mathrm{k}}$ converges to $\theta(1)$ as k goes to infinity, but it will be useful to distinguish between finite horizon effects, $\Phi_{\mathrm{k}}$ for finite $\mathrm{k}$, and long-run effects, $\theta(1)$, in the following analysis. If $\Theta_{\mathrm{YD}}=0$, aggregate demand would have no effect on output in the long run. We abandon this assumption and present our alternative structural assumptions in Section IV.

\section{The Statistical Model's Moving Average Representation}

The statistical model is Blanchard and Quah's decomposition of output into permanent and transitory shocks. Let the moving average representation for this statistical model be:

$$
\Delta \mathrm{X}_{\mathrm{t}}=\mathrm{C}(\mathrm{L}) \mu_{\mathrm{t}}
$$

where $\mu_{t}=\left(\mu_{t}^{\mathrm{P}}, \mu_{t}^{\mathrm{T}}\right)^{\prime}$ represents the vector of permanent and transitory shocks, respectively, and $\mathrm{C}(\mathrm{L})=\mathrm{C}_{0}+\mathrm{C}_{1} \mathrm{~L}+\mathrm{C}_{2} \mathrm{~L}^{2}+\ldots=\sum_{\mathrm{j}=0}^{\infty} \mathrm{C}_{\mathrm{j}} \mathrm{L}^{\mathrm{j}}$ are the impulse responses of $\Delta \mathrm{X}$ to these shocks. $\mathrm{C}_{\mathrm{j}}$ is a $2 \times 2$ matrix for all non-negative integer values of $\mathrm{j}$. In nearly all applications, the permanent and 
transitory shocks are assumed uncorrelated, and so once again it is convenient to normalize the variance of each of these shocks to one: $E \mu_{t} \mu_{t}^{\prime}=I$.

Applying the method of recursive substitution to equation (7) yields the impulse responses of output and price to the permanent and transitory shocks:

$$
\frac{\partial \mathrm{X}_{\mathrm{t}}}{\partial \mu_{\mathrm{t}-\mathrm{k}}}=\sum_{\mathrm{j}=0}^{\mathrm{k}} \mathrm{C}_{\mathrm{j}}
$$

The long-run effects these shocks have on the variables are obtained by letting k go to infinity in (8):

$$
\lim _{\mathrm{k} \rightarrow \infty}\left(\frac{\partial \mathrm{X}_{\mathrm{t}}}{\partial \mu_{\mathrm{t}-\mathrm{k}}}\right)=\sum_{\mathrm{j}=0}^{\infty} \mathrm{C}_{\mathrm{j}}=\mathrm{C}(1)
$$

with $C(1)$ representing the sum of coefficients in $C(L)$. The $C(1)$ matrix can be written as:

$$
\mathrm{C}(1)=\left[\begin{array}{cc}
\mathrm{C}_{\mathrm{YP}} & 0 \\
\mathrm{C}_{\mathrm{PP}} & \mathrm{C}_{\mathrm{PT}}
\end{array}\right]
$$

$\mathrm{C}(1)$ consists of parameters that reflect the long-run response of output or price to a permanent or transitory shock. $\mathrm{C}(1)$ was made lower triangular by setting $\mathrm{C}_{\mathrm{YT}}=0$, the restriction that forces a temporary shock to have no long-run effect on output.

\section{How are the Structure and the Statistical Model Related?}

Relationships between the structure and the statistical model are derived by mapping each of these representations into the VAR. The statistical decomposition is transformed into the VAR by multiplying (7) by $\mathrm{C}_{0} \mathrm{C}(\mathrm{L})^{-1}$. The structure is transformed into the VAR by multiplying (2) by $\theta_{0} \theta(\mathrm{L})^{-1}$, assuming the structure is invertible. ${ }^{5}$ These two mappings determine how VAR residuals:

$$
\mathrm{e}_{\mathrm{t}}=\mathrm{C}_{0} \mu_{\mathrm{t}}=\theta_{0} \varepsilon_{\mathrm{t}}
$$

and VAR coefficients: 


$$
\beta(L)=C_{0} C(L)^{-1}=\theta_{0} \theta(L)^{-1}
$$

are functions of both the statistical model and the structure. These equations characterize the relationship between the statistical model and the structure whether or not aggregate demand has a long-run effect on output.

Given equation (11) and the identity covariance matrix assumption for the shocks in each moving average representation, the covariance matrix for residuals:

$$
\Sigma_{\mathrm{e}}=\mathrm{C}_{0} \mathrm{C}_{0}^{\prime}=\theta_{0} \theta_{0}^{\prime}
$$

is written as a function of short-run coefficients from the statistical model and as a function of short-run parameters from the structure. Setting $\mathrm{L}=1$ in equation (12) yields a relationship between the statistical decomposition, the structure and $\beta(1)$, which is a matrix characterized by the sum of VAR coefficients:

$$
\beta(1)=C_{0} C(1)^{-1}=\theta_{0} \theta(1)^{-1}
$$

The first identity in equation (14) yields: $C_{0}=\beta(1) C(1)$. Inserting this expression into the first identity in (13) and simplifying yields:

$$
\mathrm{C}(1) \mathrm{C}(1)^{\prime}=\beta(1)^{-1} \Sigma_{\mathrm{e}} \beta(1)^{\prime-1}
$$

Given lower triangularity, it is well known that the $\mathrm{C}(1)$ parameters can be obtained by the appropriate Cholesky decomposition of the matrix on the right side of $(15) .{ }^{6}$ Once these parameters are known, the dynamic response of each variable to each shock is obtained from the VAR. ${ }^{7}$

Next, the relationship between the statistical moving average representation and the structure is derived. Notice that the last identify in (14) yields: $C_{0}=\theta_{0} \theta(1)^{-1} C(1)$. Insert this equation into the second equality of (13), and simplify to obtain:

$$
\mathrm{C}(1) \mathrm{C}(1)^{\prime}=\theta(1) \theta(1)^{\prime} .
$$

From the second identities in equations (12) and (14), we derive the following:

$$
C(L)=\theta(L) \theta(1)^{-1} C(1)
$$


or equivalently:

$$
\mathrm{C}_{\mathrm{j}}=\theta_{\mathrm{j}} \theta(1)^{-1} \mathrm{C}(1) \quad \text { for all } \mathrm{j}
$$

Definitions of $\theta(1)$ and $C(1)$ from (6) and (10), respectively, are used in equation (16), from it is straightforward to determine how the coefficients from the statistical model are related to long-run structural parameters: ${ }^{8}$

$$
C_{\mathrm{YP}}=\left(\Theta_{\mathrm{YS}}^{2}+\Theta_{\mathrm{YD}}^{2}\right)^{1 / 2}, C_{\mathrm{PP}}=\frac{\Theta_{\mathrm{YS}} \Theta_{\mathrm{PS}}+\Theta_{\mathrm{YD}} \Theta_{\mathrm{PD}}}{\left(\Theta_{\mathrm{YS}}^{2}+\Theta_{\mathrm{YD}}^{2}\right)^{1 / 2}} \text { and } C_{\mathrm{PT}}=\frac{\Theta_{\mathrm{YS}} \Theta_{\mathrm{PD}}-\Theta_{\mathrm{YD}} \Theta_{\mathrm{PS}}}{\left(\Theta_{\mathrm{YS}}^{2}+\Theta_{\mathrm{YD}}^{2}\right)^{1 / 2}}
$$

From these three equations, it is simple to calculate:

$$
\theta(1)^{-1} \mathrm{C}(1)=\frac{\left[\begin{array}{cc}
\Theta_{\mathrm{YS}} & -\Theta_{\mathrm{YD}} \\
\Theta_{\mathrm{YD}} & \Theta_{\mathrm{YS}}
\end{array}\right]}{\left(\Theta_{\mathrm{YS}}^{2}+\Theta_{\mathrm{YD}}^{2}\right)^{1 / 2}} .
$$

Inserting (18) into (8) and using the definition of structural responses from (3), the impulse responses from the statistical model are given by:

$$
\frac{\partial \mathrm{X}_{\mathrm{t}}}{\partial \mu_{\mathrm{t}-\mathrm{k}}}=\sum_{\mathrm{j}=0}^{\mathrm{k}} \mathrm{C}_{\mathrm{j}}=\sum_{\mathrm{j}=0}^{\mathrm{k}} \theta_{\mathrm{j}} \theta(1)^{-1} \mathrm{C}(1)=\Phi_{\mathrm{k}} \theta(1)^{-1} \mathrm{C}(1)
$$

Substituting (19) and (4) into (20) yields:

$$
\frac{\partial \mathrm{X}_{\mathrm{t}}}{\partial \mu_{\mathrm{t}-\mathrm{k}}}=\frac{\left[\begin{array}{cc}
\Phi_{\mathrm{k}}^{\mathrm{YS}} & \Phi_{\mathrm{k}}^{\mathrm{YD}} \\
\Phi_{\mathrm{k}}^{\mathrm{PS}} & \Phi_{\mathrm{k}}^{\mathrm{PD}}
\end{array}\right]\left[\begin{array}{cc}
\Theta_{\mathrm{YS}} & -\Theta_{\mathrm{YD}} \\
\Theta_{\mathrm{YD}} & \Theta_{\mathrm{YS}}
\end{array}\right]}{\left(\Theta_{\mathrm{YS}}^{2}+\Theta_{\mathrm{YD}}^{2}\right)^{1 / 2}} .
$$

Equation (21) shows the general relationship between the statistical model's impulse response functions and the structure. Clearly, if $\Theta_{Y D}=0$, the statistical model identifies structural responses. Otherwise, the statistical model's impulse responses will not generally be equivalent to structural responses. 


\section{Structural Assumptions and an Implication}

Economic theory often places bounds on the qualitative response of a variable to a structural shock. ${ }^{9}$ For example, most theories predict that a positive aggregate supply shock will cause the price level to fall:

$$
\text { A1: } \quad \frac{\partial \mathrm{P}_{\mathrm{t}}}{\partial \varepsilon_{\mathrm{t}-\mathrm{k}}^{\mathrm{S}}}=\Phi_{\mathrm{k}}^{\mathrm{PS}}<0 \quad \text { for } \mathrm{k} \geq 0 .
$$

This assumption allows for the possibility that supply shocks also shift the aggregate demand curve. If supply shocks cause both curves to shift in the same direction, then assumption A1 requires that the demand curve not shift by as much as supply. Hence, a supply shock may have a wealth effect, but A1 places an upper bound on the magnitude of that effect. An example of an aggregate supply factor that shifts both curves in the same direction is a permanent increase in productivity. This beneficial supply shock raises capital's expected future marginal product which increases investment demand, causing aggregate demand to shift to the right. Changes in marginal tax rates can also have both supply-side and demand side effects.

While assumptions about the dynamic responses of the price level to shocks are required, we will only need to be concerned with the long-run response of output to an aggregate supply shock. We make the uncontroversial assumption that a positive aggregate supply shock raises output in the long run: ${ }^{10}$

$$
\text { A2: } \quad \lim _{\mathrm{k} \rightarrow \infty} \frac{\partial \mathrm{Y}_{\mathrm{t}}}{\partial \varepsilon_{\mathrm{t}-\mathrm{k}}^{\mathrm{S}}}=\Theta_{\mathrm{YS}}>0
$$

Finally, a positive aggregate demand shock is assumed to cause the price level to rise:

$$
\text { A3: } \quad \frac{\partial \mathrm{P}_{\mathrm{t}}}{\partial \varepsilon_{\mathrm{t}-\mathrm{k}}^{\mathrm{D}}}=\Phi_{\mathrm{k}}^{\mathrm{PD}}>0 \quad \text { for } \mathrm{k} \geq 0 \text {. }
$$

If a beneficial aggregate demand shock also causes long-run aggregate supply to shift to the left $\left(\Theta_{\mathrm{YD}}<0\right)$, then A3 will hold because the movement of each curve raises the price level. On the other hand, if a 
beneficial shock to aggregate demand also shifts aggregate supply to the right $\left(\Theta_{\mathrm{YD}}>0\right)$, then for $\mathrm{A} 3$ to hold the supply curve must not shift by as much as aggregate demand does.

Assumptions A1 through A3 are consistent with a wide range of different economic structures. An important advantage to our assumptions is that long-run neutrality of aggregate demand is neither assumed nor ruled out because $\Theta_{\mathrm{YD}}$ is unconstrained.

Using permanent and transitory shock decompositions with pre-World War I data for countries that have relatively long samples of data, Keating and Nye (1998) found that a permanent increase in output is associated with an increase in the price level in 8 of the 10 countries in their study. In 5 cases, these positive price responses are statistically significant. This evidence rejects the assumptions underlying Blanchard and Quah's decomposition because if permanent shocks are aggregate supply shocks, price and output are expected to move in opposite directions. But a rejection of that structural model is not all that we can infer from this evidence.

Proposition: If a permanent increase in output is associated with an increase in the price level, then aggregate demand must have a positive effect on output in the long run.

Proof: The response of price to a permanent increase in output is obtained from equation (21):

$$
\frac{\partial \mathrm{P}_{\mathrm{t}}}{\partial \mu_{\mathrm{t}-\mathrm{k}}^{\mathrm{P}}}=\frac{\Phi_{\mathrm{k}}^{\mathrm{PS}} \Theta_{\mathrm{YS}}+\Phi_{\mathrm{k}}^{\mathrm{PD}} \Theta_{\mathrm{YD}}}{\left(\Theta_{\mathrm{YS}}^{2}+\Theta_{\mathrm{YD}}^{2}\right)^{1 / 2}}
$$

From the inequality that makes this price response positive, it is easy to show:

$$
\Theta_{\mathrm{YD}}>\frac{-\Phi_{\mathrm{k}}^{\mathrm{PS}} \Theta_{\mathrm{YS}}}{\Phi_{\mathrm{k}}^{\mathrm{PD}}}
$$

Assumptions A1, A2 and A3, guarantee that the right side of the inequality is positive. Q.E.D. 


\section{Conclusions}

Even when their long-run identifying restriction is not a valid structural assumption, Blanchard and Quah's decomposition may still be able to discover important qualitative features of an economy. This paper provides a structural interpretation for one of the most puzzling empirical findings in Keating and Nye (1998). That finding implies, under a relatively weaker set of structural assumptions, that aggregate demand had a permanent effect on output in a number of prewar economies with an increase (decrease) in aggregate demand raising (lowering) output in the long run.

A number of different structures exist that may allow aggregate demand to have this type of longrun effect. Examples include hysteresis in labor markets, coordination failures, non-superneutrality of money and government spending that crowds-in investment in the long run. Our analysis points to the need for empirical work that formally tests for these and possibly other structures in pre-World War I economies. And, even though structural VAR results for the postwar are typically consistent with a textbook macro model, it might be useful to test postwar data for any structures found to be relevant in the prewar period. It is possible the mechanisms that induce non-neutrality of aggregate demand in prewar economies are still relevant, but that they for some reason difficult to detect in postwar data with Blanchard and Quah decompositions. 


\section{Notes}

1. Our specification substitutes price level data for the unemployment rate used by Blanchard and Quah. See Keating and Nye (1998) for a discussion of possible advantages to this substitution.

2. It is helpful to define a simple term that summarizes the class of economic theories that have been used to justify Blanchard and Quah's statistical model. We recognize there are more sophisticated textbooks, particularly for graduate courses, that formally develop theories in which aggregate demand is not longrun neutral. Such theories are a primary motivation for the analysis in this paper.

3. Keating (2012) studies the implications of two other empirical results from the empirical literature, and finds that they also provide support for the hypothesis that aggregate demand had a long-run positive output effect in prewar economies.

4. Cover, Enders and Hueng (2006) question the assumption that aggregate demand and supply shocks are uncorrelated and abandon that restriction in favor of an alternative identifying assumption.

5. Fernández-Villaverde, Rubio-Ramírez, Sargent and Watson (2007) develop a general condition that can be used to check for invertibility in a structure.

6. Christiano, Eichenbaum and Vigfusson (2006) use alternative estimators of the zero-frequency spectral density matrix in place of the VAR estimates on the right hand side of (15), and find that the alternatives have better sampling properties.

7. The complete dynamic response of each variable to each shock is obtained analytically by inserting $\mathrm{C}(1)$ into the first equality from (14), solving for $\mathrm{C}_{0}$, inserting $\mathrm{C}_{0}$ into the first equality in (12), and solving for $\mathrm{C}(\mathrm{L})$. In practice, responses are generated by dynamic simulation of the VAR model.

8. Each parameter has two solutions that are equivalent in absolute value and opposite in sign. The solution that one selects amounts to whether you are plotting the impulse responses to a positive or a negative shock. We chose the positive solution for $\mathrm{C}_{\mathrm{YP}}$ because researchers typically report the impulse responses of the variables to a permanent positive shock to output.

9. Faust (1998), Canova and De Nicoló (2002) and Uhlig (2005), for example, use sign restrictions to identify VARs. Our application of sign restrictions is fundamentally different. We use them to address the structural implications of a misspecified model. Waggoner and Zha (2003) discuss inference problems that can arise from inappropriately normalizing equations in a simultaneous system, giving some attention to the implications of their analysis for the work of Faust and Uhlig. Waggoner and Zha point out that recursive models are immune to such problems. Since we study a recursive statistical model, our analysis is also immune to these concerns about improper normalization.

10. This allows output to rise, fall or remain unchanged immediately after a supply shock occurs, consistent with Basu, Fernald and Kimball (2006). 


\section{References}

Basu, Susanto, John Fernald and Miles Kimball (2006) "Are Technology Improvements Contractionary?," The American Economic Review Vol. 96, No. 5, December, 1418-1448.

Blanchard, Olivier J. and Danny Quah (1989) "The Dynamic Effects of Aggregate Demand and Supply Disturbances," American Economic Review, 79: 655-673.

Canova, Fabio and Gianni De Nicoló, (2002) "Money Matters for Business Cycle Fluctuations in the G7," Journal of Monetary Economics, 49, 1131-1159.

Christiano, Lawrence J., Martin Eichenbaum and Robert Vigfusson (2006) "Alternative Procedures for Estimating Vector Autoregressions Identified with Long-Run Restrictions," Journal of the European Economic Association, vol. 4(2-3), 475-483.

Cover, James Peery, Walter Enders and C. James Hueng (2006) "Using the Aggregate DemandAggregate Supply Model to Identify Structural Demand-Side and Supply-Side Shocks: Results Using a Bivariate VAR," Journal of Money, Credit and Banking. 38(3): 777-790

Faust, Jon (1998) “The Robustness of Identified VAR Conclusions about Money," Carnegie-Rochester Conference Series on Public Policy, Volume 49, December, 207-244.

Fernández-Villaverde, Jesus, Juan Rubio-Ramírez, Thomas J. Sargent and Mark Watson (2007) "ABCs (and Ds) of Understanding VARs," American Economic Review, American Economic Association, vol. 97(3), pages 1021-1026, June.

Keating, John W. and John V. Nye (1998) "Permanent and Transitory Shocks in Real Output: Estimates from Nineteenth Century and Postwar Economies," Journal of Money, Credit, and Banking 30, May, 231-251.

Keating John W. (2012) "Interpreting Permanent and Transitory Shocks to Output when Aggregate Demand May Not be Neutral in the Long-Run: Further Results," University of Kansas Working Paper

Uhlig, Harald (2005) "What are the Effects of Monetary Policy on Output? Results from an Agnostic Identification Procedure," Journal of Monetary Economics 52:381-419.

Waggoner, Daniel F. and Tao Zha (2003) "Likelihood Preserving Normalization in Multiple Equation Models," Journal of Econometrics, Volume: 114, Issue: 2, June, 329-347. 